\title{
Myelopathy following Intrathecal Chemotherapy in a Patient with Extensive Burkitt's Lymphoma and Altered Immune Status
}

\author{
SUSAN BATES, M.D. \\ Bethesda, Maryland \\ PAUL MCKEEVER, M.D. \\ Ann Arbor, Michigan \\ HENRY MASUR, M.D. \\ DAVID LEVENS, M.D., Ph.D. \\ ABE MACHER, M.D. \\ GARY ARMSTRONG, B.S.M.T. \\ IAN T. MAGRATH, M.B., M.R.C.P. \\ Bethesda, Maryland
}

From the Clinical Oncology Program, Division of Cancer Treatment, National Cancer Institute, the Critical Care Medicine Department, Clinical Center, and the Laboratory of Pathology, Division of Cancer Biology and Diagnosis, National Cancer Institute, National Institutes of Health, Bethesda, Maryland, the Department of Pathology, University of Michigan Medical School, Ann Arbor, Michigan, and the Food and Drug Administration. Bureau of Biologics, Division of Virology, Bethesda, Maryland. Requests for reprints should be addressed to Dr. lan T. Magrath, Pediatric Branch, Building 10, Room 13N240, National Cancer Institute, Bethesda, Maryland 20205. Manuscript accepted May 24, 1984

\begin{abstract}
A 30-year-old homosexual man presented with widespread Burkitt's Iymphoma. On the basis of immunologic and viral studles, he was suspected of having the acquired immune deflciency syndrome. Following chemotherapy that included intrathecal cytosine arabinoside and methotrexate, brain stem edema, paraplegla, and an elevated cerebrospinal filuid level of myelin basic protein developed. Autopsy revealed vacuolar demyelination of spinal cord, bralin stem, and cerebellum. The pathologic findings were similar to those reported to occur in myelopathy assoclated with intrathecal chemotherapy, but far more extensive. The contribution of the suspected acquired Immune deficiency syndrome is unknown.
\end{abstract}

Although a variety of toxicities have been reported after intrathecal chemotherapy, in many patients it may be difficult to determine the relative contributions of the therapy and the underlying malignancy. Recently, there have been reports of the development of undifferentiated lymphoma in patients with the acquired immune deficiency syndrome (AIDS) [1]. Since involvement of the nervous system by the lymphoma is common in such patients, intrathecal chemotherapy is a vital component of treatment. Yet these patients are highly susceptible to a variety of infections, many involving the nervous system, and neurologic syndromes of unknown origin have also been described. Patients with this syndrome may therefore be at particular risk of neurologic complications of therapy.

We describe herein a 30-year-old homosexual man with extensive Burkitt's lymphoma and suspected AIDS in whom a myelopathy developed after chemotherapy that included intrathecal treatment. The myelopathy, which extended into the brain stem and resulted in increased intracranial pressure, was more severe than cases previously reported and led to the patient's death. None of the neurologic disorders usually described in AIDS could account for the noninflammatory vacuolar demyelination that involved spinal cord, brain stem, and cerebellum. However, an underlying abnormal immune system may have contributed to the extensive nature of the presumptive neurotoxic reaction.

\section{CASE REPORT}

A 30-year-old white homosexual man was admitted with progressive stupor, fever, weakness, and disconjugate gaze. He had no significant past medical history, but four months earlier he had noted the onset of marked fatigue and an eight-pound weight loss. One month prior to admission, biopsy of an enlarged right cervical node revealed reactive hyperplasia. At that time, his hemoglobin level was $11.9 \mathrm{~g} / \mathrm{dl}$, lactic dehydrogenase level $420 \mathrm{lU} / \mathrm{liter}$, and 
TABLE I Viral Cultures and Serologic Studies

\begin{tabular}{|c|c|c|c|c|}
\hline & \multicolumn{2}{|c|}{ Serologic Studies } & \multicolumn{2}{|c|}{ Cultures } \\
\hline & Antibody & Titer & Specimen & Result \\
\hline Epstein-Barr virus & $\begin{array}{l}\text { Viral capsid antigen } \\
\text { Early antigen } \\
\text { Epstein-Barr virus nucleic acid }\end{array}$ & $\begin{array}{l}1: 1,280 \\
1: 80 \\
1: 20\end{array}$ & Throat & + \\
\hline Cytomegalovirus & $\begin{array}{l}\lg G \\
\lg M\end{array}$ & $\begin{array}{l}1: 3,200 \\
-\end{array}$ & $\begin{array}{l}\text { Throat } \\
\text { Blood } \\
\text { Urine } \\
\text { Lung tissue (postmortem) }\end{array}$ & $\begin{array}{l}- \\
+ \\
+ \\
+\end{array}$ \\
\hline Herpes simplex virus & & & Sacral lesion & + \\
\hline
\end{tabular}

erythrocyte sedimentation rate $88 \mathrm{~mm}$ per hour. One week prior to admission, he was noted to have mild lymphadenopathy and oral candidiasis. His creatine phosphokinase level was 2,900 IU/liter and lactic dehydrogenase level 3,060 IU/liter. Stupor and gaze paresis then developed which led to his referral.

On admission, he was cachectic and stuporous but responsive to questions. His temperature was $39^{\circ} \mathrm{C}$, and respiratory rate 36 per minute. The right pupil was $6 \mathrm{~mm}$ and sluggishly reactive to light; the left was $3 \mathrm{~mm}$ and reacted normally. There was complete palsy of all extraocular muscles. Right-sided rales were noted on examination of the chest, and heart examination showed normal findings. Hepatosplenomegaly was present: the liver span was $17 \mathrm{~cm}$ and the spleen was papable $4 \mathrm{~cm}$ below the costal margin. The left testis was enlarged and indurated. Small ulcerated lesions from which herpes simplex virus was cultured were observed on the buttocks. Mild generalized lymphadenopathy was noted.

The white blood cell count was $12,800 / \mathrm{mm}^{3}$, the hemoglobin level $10.3 \mathrm{~g} / \mathrm{dl}$, and the platelet count $81,000 / \mathrm{mm}^{3}$. Abnormal chemical values included: serum glutamic oxaloacetic transaminase $305 \mathrm{IU} /$ liter, serum glutamic pyruvic transaminase $165 \mathrm{lU} /$ liter, lactic dehydrogenase 3,710 IU/. liter, alkaline phosphatase $215 \mathrm{lU} / \mathrm{liter}$, uric acid $16 \mathrm{mg} / \mathrm{dl}$, lactate $12.1 \mathrm{mg} / \mathrm{dl}$, glucose $36 \mathrm{mg} / \mathrm{dl}$, and creatine phosphokinase $1,400 \mathrm{IU} /$ /iter (100 percent $\mathrm{mm}$ fraction). The cerebrospinal fluid was xanthochromic and bloody. Bilateral pleural effusions were seen on chest radiography. Ultrasound of the abdomen demonstrated hepatosplenomegaly with two solid masses within the liver.

Results of tests for hepatitis B core and surface antibody were positive. Elevated titers to cytomegalovirus and Epstein-Barr virus were also noted (Table I). Immunologic studies revealed marked depression of lymphocyte proliferation in response to cytomegalovirus antigen and concanavalin A, elevated interferon levels, and an inverted T4:T8 ratio $(0.42$; normal greater than 1.6$)$.

Burkitt's lymphoblasts were seen in the peripheral blood (1 percent), pleural fluid, and spinal fluid. Lymph node and bone marrow biopsy specimens revealed Burkitt's lymphoma. Tumor cells trom several sources were Epstein-Barr virus nuclear antigen-positive, and DNA hybridization studies demonstrated 40 Epstein-Barr virus genome equivalents per cell (G. Miller, personal communication). Karyotyping revealed an 8;22 translocation [2].
On the third hospital day, $1,900 \mathrm{mg}$ of cyclophosphamide $\left(1,200 \mathrm{mg} / \mathrm{m}^{2}\right)$ was administered intravenously. Fifty milligrams of cytosine arabinoside $\left(30 \mathrm{mg} / \mathrm{m}^{2}\right)$ were given intrathecally on the second, third, fourth, and eighth hospital days. On the 12th hospital day, he received $12.5 \mathrm{mg}$ of methotrexate intrathecally and a 42-hour infusion of high-dose methotrexate, followed by leucovorin rescue.

There was dramatic improvement with resolution of the pleural effusion, lymphadenopathy, hepatosplenomegaly, testicular enlargement, and abnormal chemical values, and an improvement in eye movement. Burkitt's cells were no longer seen in the spinal fluid. Repeated bone marrow biopsy revealed no lymphoma cells, and ultrasound showed resolution of the focal hepatic defects.

Lumbar puncture was performed on the 29th hospital day for a further intrathecal injection of cytosine arabinoside. On the following day, his temperature rose to $38.6^{\circ} \mathrm{C}$ but an infectious cause was not confirmed. On the 35 th hospital day, the patient received intravenously $1,824 \mathrm{mg}$ of cyclophosphamide $\left(1,200 \mathrm{mg} / \mathrm{m}^{2}\right), 60 \mathrm{mg}$ of doxorubicin hydrochloride $\left(40 \mathrm{mg} / \mathrm{m}^{2}\right), 2 \mathrm{mg}$ of vincristine, and $60 \mathrm{mg}$ of prednisone (40 $\mathrm{mg} / \mathrm{m}^{2}$ ). He was also given two of three scheduled daily 50 $\mathrm{mg}$ doses of intrathecal cytosine arabinoside. After the first dose, nausea and vomiting developed, and after the second dose his temperature rose to $39.1^{\circ} \mathrm{C}$. Results of multiple blood cultures remained negative. He complained of bilateral hip pain. Subsequently, there was decreasing responsiveness, hypertension, bradycardia, and hypothermia. There was no papilledema, and the lower extremities were flaccid with loss of pinprick sensation. Opening pressure on lumbar puncture was $30 \mathrm{~cm}$ of water. Cerebrospinal fluid protein level was $1,160 \mathrm{mg} / \mathrm{dl}$ and white cell count $21 / \mathrm{mm}^{3}$, but no tumor cells were present. After the lumbar puncture, obtundation and hypoventilation developed. Mannitol and dexamethasone were given. Computed tomography revealed brain stem edema, marked enlargement of both lateral ventricles, and obliteration of the third and fourth ventricles. After ventriculostomy, the patient's condition slowly improved. He was alert, able to squeeze with both hands, but unable to move his lower extremities despite painful stimuli. There was coarse horizontal nystagmus. Repeated scanning showed a marked decrease in the size of the ventricles. Six days after insertion, the shunt was removed and the patient became unresponsive. A major intracerebral hemorrhage was found by computed tomography, and he died on the following day. 
Figure 1. Vacuolar demyelination in dorsal spinocerebellar tract of mid-cervical spinal cord. Phagocytosed myelin can be seen in a macrophage (arrowhead) (Luxol fast blue and perlodic acidSchiff stain; original magnification $\times 660$, reduced by 30 percent).

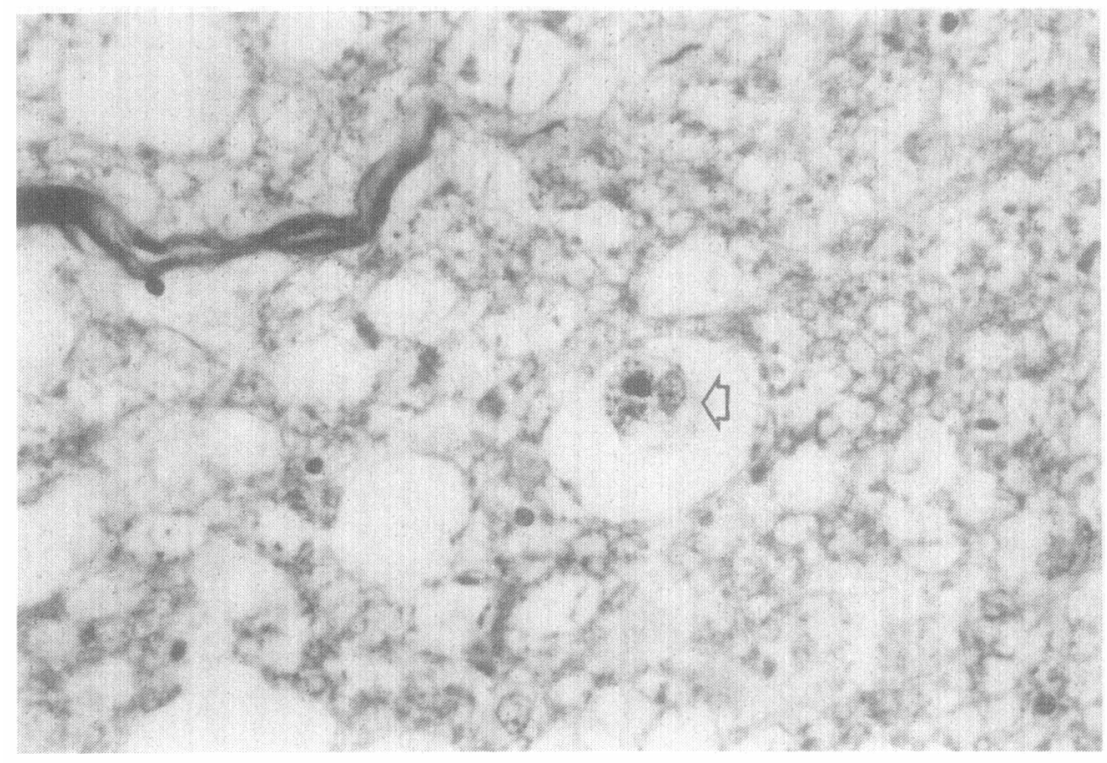

Aulopsy Findings. Autopsy revealed necrotic lymphoma in marrow and pleura, and fibrosis in the testes. There was a large fresh hemorrhage in the tract of the ventricular shunt, with blood in all ventricles and subarachnoid space.

Histologic examination showed noninflammatory, vacuolar demyelination of the white matter of the spinal cord (Figure 1), brain stem, tuber cinereum, and cerebellum and myelinated axons of the cerebellar granular layer. The mildest changes consisted of multiple microvacuoles in myelin and axonal swellings (spheroids). Swelling of oligodendroglial cytoplasm was variably present, and multiple areas of demyelination with preferential loss of large diameter axons were also observed. Most of the damage was within white matter not more than $1 \mathrm{~cm}$ from the subarachnoid space.

In the spinal cord, vacuolar demyelination was bilateral and nearly symmetric. Myelin loss was most severe at depths of 100 to 1,000 microns from the outer margin of white matter (Figure 2). A peripheral 50- to 200-micron rim of white matter in the region supplied by the arterial vasocorona was less affected. Damage overlapped adjacent tracts and was severe in the upper thoracic level. Medial portions of spinocerebellar tract and lateral portions of corticospinal and spinothalamic, cuneate, gracilis, and vestibulospinal tracts were involved.

In the brain stem, vacuolar demyelination was most severe in the medulla where pyramids and olivocerebellar fibers were involved bilaterally. Corticospinal demyelination was present in the pons and cerebral peduncles.

Cerebellar vacuolar demyelination of the white matter was multifocal and most extensive in the folia. The demyelination extended to the granular cell layer without affecting the number of granular cells. As in other affected regions, axonal swellings were conspicuous (Figure 3 ).

There was no viable lymphoma, no lesions suggestive of toxoplasmosis, and organisms were not seen on special stains. No inflammation was present, viral inclusions were not found, and results of immunoperoxidase examinations for polyoma viruses were negative. Cerebrospinal fluid that had been stored during life was sent for myelin basic protein analysis. Results are shown in Figure 4.

\section{COMMENTS}

The findings in this patient were probably a consequence of unusually severe neurotoxicity associated with intrathecal chemotherapy occurring in a patient with suspected AIDS. Shortly after intrathecal cytosine arabinoside, nausea, vomiting, and fever developed, followed by bilateral hip pain and lethargy and then by signs of an intracranial herniation. There was evidence of paraplegia, which persisted until his death. It is not certain that this patient's neurologic complications were unequivocally due to the chemotherapy. However, the temporal relationship of onset of symptoms to the in-

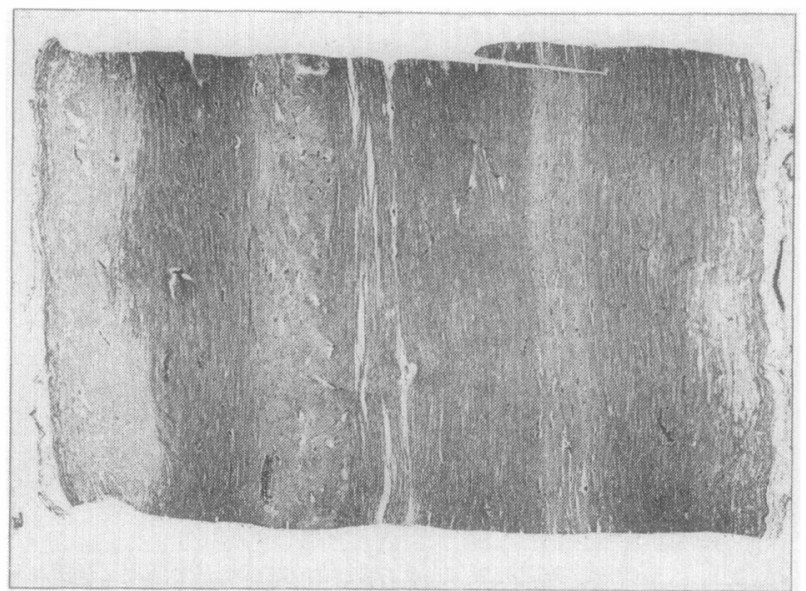

Flgure 2. Peripheral vacuolar demyelination in longitudinal section of lower thoracic spinal cord (hematoxylin and eosin stain; original magnification $\times 11.5$, reduced by 30 percent). 


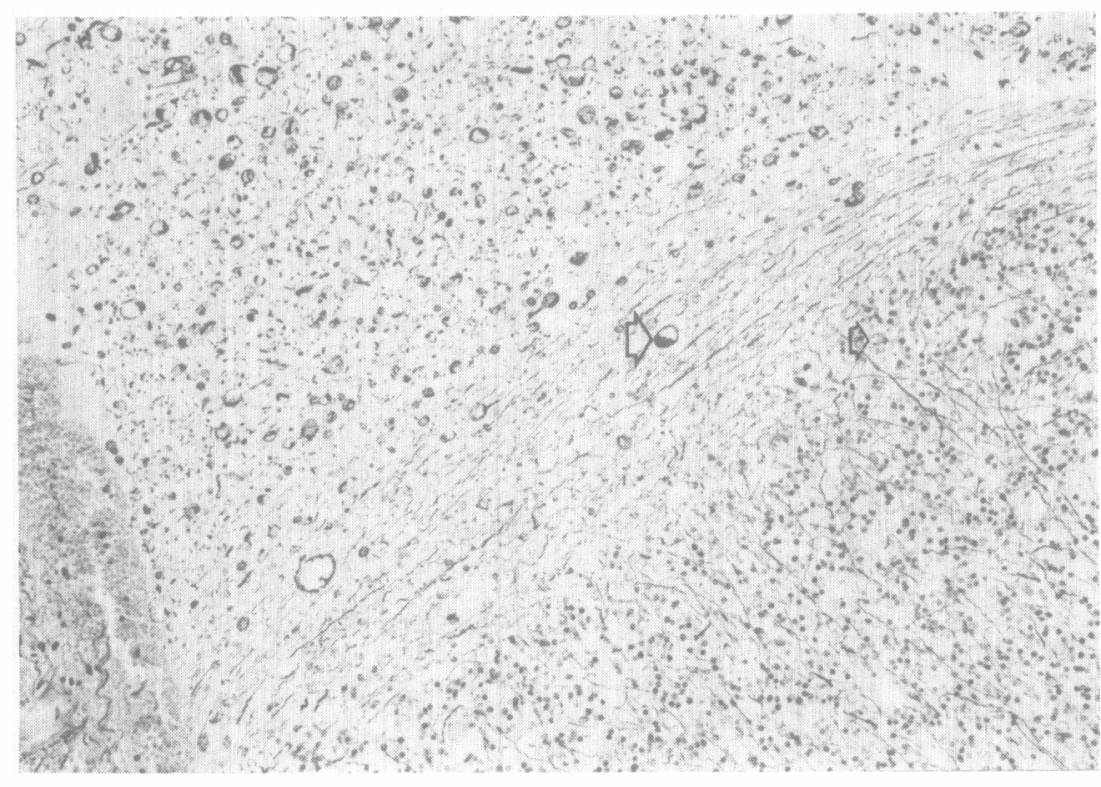

Flgure 3. Cerebellar folium. Axonal swellings are numerous in the secondary lamina of white matter (upper lett). Axonal swellings are also present in the primary lamina of white matter (large arrowhead) and in the granular cell layer (small arrowhead) (Bodian's stain for axons; original magnification $\times 175$, reduced by 30 percent). trathecal cytosine arabinoside is suggestive, particularly in view of the findings on pathologic examination. The clinical picture differed in some respects from that previously reported in cases in which myelopathy was associated with intrathecal chemotherapy. As in other cases, the onset was acute; there was a suggestion of radicular pain with the hip pain, and there was both motor and sensory loss. Unlike other cases, the pathologic changes extended into the brain stem, causing edema, cerebrospinal fluid outflow obstruction, and a herniation syndrome.

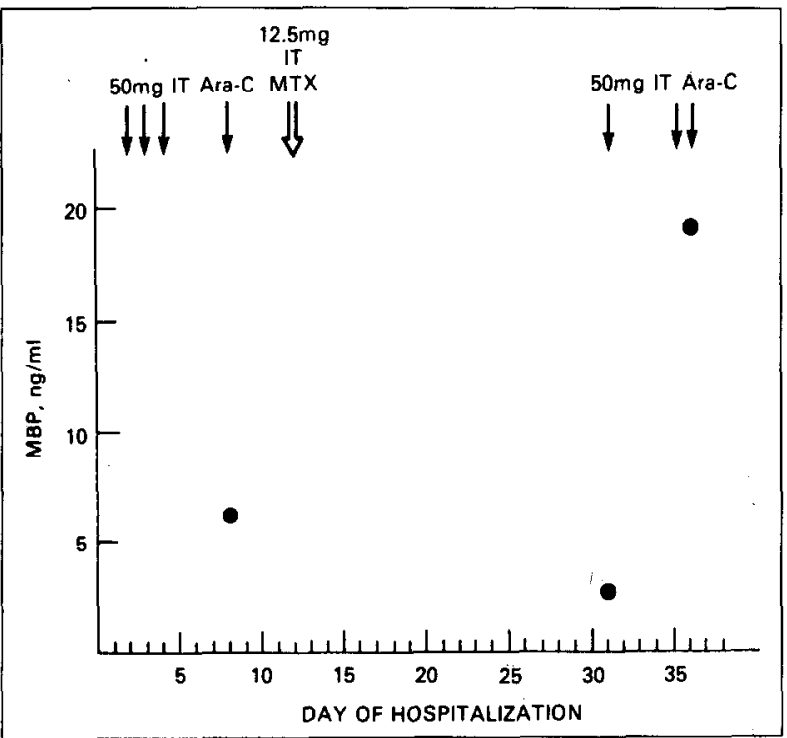

Flgure 4. Cerebrospinal fluid myelin basic protein (MBP) levels. Graph shows relationship to intrathecal (IT) chemotherapy. The upper limit of normal is $5 \mathrm{ng} / \mathrm{ml}$. Ara-C $=c y$ tosine arabinoside; $M T X=$ methotrexate.
Although the presence of AIDS in this patient cannot be proved, it was suspected in view of the usual clinical presentation for Burkitt's lymphoma, with widespread disease, and the associated immunologic study results including impaired lymphocyte proliferation and a decreased ratio of helper to suppressor T cells. Ziegler et al [1] recently described four homosexual males with a Burkitt's-like lymphoma. These patients also had unusual presentations for Burkitt's lymphoma; three had central nervous system involvement.

Neurologic disorders have been reported in 10 to 20 percent of patients with AIDS. A large fraction of these patients have intracerebral mass lesions, frequently due to Toxoplasma gondii or non-Hodgkin's lymphoma [3]. In some lesions, biopsy or autopsy material has been nondiagnostic, showing a few viral inclusion bodies or nonspecific inflammatory reaction.

Other prominent neurologic manifestations of AIDS include a progressive global dementia in which cerebral biopsy specimens have shown nonspecific inflammatory changes and extensive demyelinization. Progressive multifocal leukoencephalopathy with cerebellar demyelination due to $\mathrm{JC}$ virus has also been reported [4]. Meningitis, particularly cryptococcal meningitis, has also been common, typically with subtle clinical presentations. Finally, a peripheral neuropathy of unknown origin has developed in many patients with AIDS. In the case presented, none of these possibilities could be shown to be responsible for the neurologic abnormalities.

Neurotoxicity associated with both cytosine arabinoside and methotrexate has been described. Methotrexate toxicity has included chemical arachnoiditis, paraparesis, and disseminated necrotizing leukoencephalopathy [5-8]. Rarely, death has occurred im- 
mediately after intrathecal injection of methotrexate [9]. Neurotoxicity with cytosine arabinoside has been described less frequently, but transient or permanent paraparesis and seizures have been observed [1012].

Multiple case reports of paraparesis following intrathecal cytosine arabinoside and methotrexate have appeared in the literature $[5,7,9,10,12-22]$, with intrathecal methotrexate most commonly involved. Frequently there was radicular pain. The onset of dysfunction was usually immediate, and in most cases less than $\mathbf{4 0}$ hours. It was typically transient, but in some the neurologic deficits progressed or ascended over hours or days, with paraplegia and sensory levels as high as C7. In several cases, the deficit appeared permanent.

There are few reported cases of neurotoxicity associated with cytosine arabinoside alone. Wolff et al [12] described a 27-year-old patient with acute myelogenous leukemia who received central nervous system prophylaxis with five $170 \mathrm{mg}\left(100 \mathrm{mg} / \mathrm{m}^{2}\right)$ doses of intrathecal cytosine arabinoside and cranial irradiation, followed in one month by lower extremity paresthesias and weakness. Breuer et al [10] reported a case of paraparesis following four $84 \mathrm{mg}$ doses given for prophylaxis concurrent with cranial irradiation. Two weeks later, gait disturbance, lower extremity weakness, sensory loss, and urinary incontinence developed.

In none of these cases of paraplegia did herniation syndromes appear. However, Eden et al [11] reported the development of fever and generalized seizures after intrathecal cytosine arabinoside injection in two children. One of the children had signs of cerebral herniation that responded to dexamethasone and mannitol.

Various suggestions have been made concerning the pathogenesis of cytosine arabinoside or methotrexate neurotoxicity, but none of them has been proved $[7,10,15,18,23]$. Only a few of the patients have undergone post mortem examination, which has revealed demyelination of the cord. Simple removal and reinjection of $1 \mathrm{cc}$ aliquots of cerebrospinal fluid has been noted to cause demyelination with posterior extremity paralysis in cats [24].

The syndrome of myelopathy following intrathecal chemotherapy is distinct from that of necrotizing leukoencephalopathy associated with systemic or intrathecal methotrexate and cranial irradiation $[6,8,23,25]$. The latter syndrome is characterized by demyelination in the brain tissue plus multifocal necrosis, astrocytosis, and occasionally dystrophic calcification. Levels of myelin basic protein, which is specific to the myelin sheath, are elevated in the cerebrospinal fluid [21], as in multiple sclerosis, in which levels of myelin basic protein correlate with the degree of active demyelination $[26,27]$.
With few exceptions, cerebrospinal fluid myelin basic protein levels have not been recorded in patients with myelopathy due to intrathecal chemotherapy. Gangji et al [21] noted a transiently elevated level in a patient with acute-onset, right-sided hemiparesis after prophylactic intrathecal methotrexate and cranial irradiation. Clark et al [22] described a patient who had had numerous courses of intrathecal methotrexate and cytosine arabinoside for central nervous system leukemia of long duration, and in whom sensory loss and paraplegia developed accompanied by a myelin basic protein level of $17 \mathrm{ng} / \mathrm{ml}$ four weeks after bone marrow transplantation. A fatal ascending myelopathy characterized by a myelin basic protein level greater than $40 \mathrm{ng} / \mathrm{ml}$ developed in a patient at the National Cancer Institute after extensive treatment for central nervous system leukemia [28]. In the patient described herein, the myelin basic protein level was weakly positive $\mathbf{6 . 0}$ $\mathrm{ng} / \mathrm{ml}$ ) after four intrathecal injections of cytosine arabinoside. After the level normalized during a period free from drug administration, more intrathecal cytosine arabinoside was given and the level rose to $19 \mathrm{ng} / \mathrm{ml}$ coincident with neurologic deterioration.

Microscopic findings in the present case were very similar to findings in the cases reported by Breuer et al [10] and Clark et al [22]. Major features in common were vacuolar myelin loss with axonal swellings but without necrosis or inflammation and with localization of the damage to myelin near the cerebrospinal fluid of the subarachnoid space. However, in the present case, destruction was not confined to the spinal cord. Vacuolar demyelination, microscopically identical to that seen in the spinal cord, affected multiple regions of brain stem and cerebellum. These regions had not been irradiated and were devoid of necrosis and calcification described in association with necrotizing leukoencephalopathy $[6,8,23,25]$. Thus, the myelopathy was more severe clinically and pathologically than any previously reported.

In summary, widespread Burkitt's lymphoma developed in a 30-year-old homosexual man with suspected AIDS. He had a complete clinical response to the first dose of cyclophosphamide but then had neurologic deterioration temporally related to intrathecal chemotherapy with cytosine arabinoside. Clinically, the initial manifestations were fever, nausea, vomiting, and bilateral hip pain. Following recovery from increased intracranial pressure due to brain stem edema, there was persistent paraplegia. On postmortem examination, extensive demyelination involving the cord and brain stem was seen, but without necrosis. Although it appeared to be a complication of intrathecal chemotherapy, a syndrome this extensive has not been previously described. Whether the suspected underlying AIDS may have been related to the development or severity of the demyelination syndrome is speculative. 


\section{REFERENCES}

1. Ziegler JL, Miner RC, Rosenbaum E, et al: Outbreak of Burkitt's-like lymphoma in homosexual men. Lancet 1982; II: $631-633$.

2. Whang-Peng J, Lee EC, Magrath IT: Burkitt's Iymphoma in AIDS. Cytogenetic study. Blood 1984; 63: 818-822.

3. Lehrich JR, Hedley-Whyte ET, Harris NL: Acquired immunodeficiency syndrome and cranial-nerve abnormalities. $\mathbf{N}$ Engl J Med 1983; 309: 359-369.

4. Miller JR, Barrett RE, Britton CB, et al: Progressive multifocal leukoencephalopathy in a male homosexual with T-cell immune deficiency. N Engl J Med 1982; 307: 14361437.

5. Sullivan MP, Windmiller J: Side effects of amethopterin (methotrexate) administered intrathecally in the treatment of meningial leukemia. Medical Record and Annals 1966; 59: $92-101$

6. Rubinstein LJ, Herman MM, Long TF, Wilbur JR: Disseminated necrotizing leukoencephalopathy: a complication of treated central nervous system leukemia and lymphoma. Cancer 1975; 35: 291-305.

7. Gagliano RG, Costanzi JJ: Paraplegia following intrathecal methotrexate. Report of a case and review of the literature Cancer 1976; 37: 1663-1668.

8. Pizzo PA, Poplack DG, Bleyer WA: Neurotoxicities of current leukemia therapy. Am J Pediatr Hematol Oncol 1979; 1: 127-140.

9. Back EH: Death after intrathecal methotrexate. Lancet 1969; II: 1005.

10. Breuer AC, Pitman SW, Dawson DM, Schoene WC: Paraparesis following intrathecal cytosine arabinoside: a case report with neuropathologic findings. Cancer 1977; 40: 2817-2822

11. Eden OB, Goldie W, Wood T, Etcubanas E: Seizures following intrathecal cytosine arabinoside in young children with acute lymphoblastic leukemia. Cancer 1978; 42: 53-58.

12. Wolff L, Zighelboim J, Gale RP: Paraplegia following intrathecal cytosine arabinoside. Cancer 1979; 43: 83-85.

13. Baum ES, Koch HF, Corby DG, Plunkett DC: Intrathecal methotrexate. Lancet 1971; I: 649.

14. Bagshawe KD, Magrath IT, Golding PR: Intrathecal methotrexate. Lancet 1969; II: 1258.

15. Saiki JH, Thompson S, Smith F, Atkinson R: Paraplegia following intrathecal chemotherapy. Cancer 1972; 29:
370-374

16. Pasquinucci G, Pardini R, Fedi F: Intrathecal methotrexate. Lancet 1970; I: 309-310.

17. Luddy RE, Gilman PA: Paraplegia following intrathecal methotrexate. J Pediatr 1973; 83: 988-992.

18. Bleyer WA, Drake JC, Chabner BA: Neurotoxicity and elevated cerebrospinal fluid methotrexate concentration in meningial leukemia. N Engl J Med 1973; 289: 770-773.

19. Reznik M: Acute ascending poliomyelomalacia after treatment of acute lymphocytic leukemia. Acta Neuropathol 1979; 45: 153-157.

20. Grisold W, Lutz D, Wolf D: Necrotizing myelopathy associated with acute lymphoblastic leukemia: case report and review of the literature. Acta Neuropathol 1980; 49: 231-235.

21. Gangji D, Reaman GH, Cohen SR, Bleyer WA, Poplack DG: Leukoencephalopathy and elevated levels of myelin basic protein in the cerebrospinal fluid of patients with acute lymphoblastic leukemia. N Engl J Med 1980; 303: 1921.

22. Clark AW, Cohen SR, Nissenblatt MJ, Wilson SK: Paraplegia following intrathecal chemotherapy: neuropathologic findings and elevation of myelin basic protein. Cancer 1982; 50: 42-47

23. Weiss HD, Walker MD, Wiernik PH: Neurotoxicity of commonly used antineoplastic agents. N Engl J Med 1974; 291: 75-81.

24. Bunge RP, Settlage PH: Neurological lesions in cats following cerebrospinal fluid manipulation. J Neuropathol Exp Neurol 1957; 16: 471-491

25. Price RA, Jameson PA: The central nervous system in childhood leukemia. II. Subacute leukoencephalopathy. Cancer 1975; 35: 306-318.

26. Cohen SR, Herndon RM, McKhann GM: Radioimmunoassay of myelin basic protein in spinal fluid: an index of active demyelination. N Engl J Med 1976; 295: 1455-1457.

27. Cohen SR, Brooks BR, Herndon RM, McKhann GM: A diagnostic index of active demyelination: myelin basic protein in cerebrospinal fluid. Ann Neurol 1980; 8: 25-31.

28. Bates SE, Raphaelson MI, Price RA, Mckeever P, Cohen S, Poplack DG: Ascending myelopathy after chemotherapy for central nervous system acute lymphoblastic leukemia: correlation with cerebrospinal fluid myelin basic protein. Med Pediatr Oncol (in press). 